\title{
Scientific Drilling at Lake Tanganyika, Africa: A Transformative Record for Understanding Evolution in Isolation and the Biological History of the African Continent, University of Basel, 6-8 June 2016
}

\author{
Andrew S. Cohen ${ }^{1}$ and Walter Salzburger ${ }^{2}$ \\ ${ }^{1}$ Department of Geosciences, University of Arizona, Tucson, AZ 85721, USA \\ ${ }^{2}$ Zoologisches Institut, Universität Basel, 4051 Basel, Switzerland \\ Correspondence to: Andrew S. Cohen (cohen@email.arizona.edu)
}

Received: 12 July 2016 - Revised: 1 September 2016 - Accepted: 19 September 2016 - Published: 31 May 2017

\begin{abstract}
We report on the outcomes of a workshop held to discuss evolutionary biology, paleobiology and paleoecology questions that could be addressed by a scientific drilling project at Lake Tanganyika, the largest, deepest and oldest of the African Rift Valley lakes. Lake Tanganyika is of special significance to evolutionary biologists as it harbors one of the most spectacular endemic faunas of any lake on earth, with hundreds of unique species of fish, molluscs, crustaceans and other organisms that have evolved over the lake's long history. Most of these groups of organisms are known from fossils in short cores from the lake, raising the possibility that both body fossil and ancient DNA records might be recovered from long drill cores. The lake's sedimentary record could also provide a record of African terrestrial ecosystem history since the late Miocene. This 3-day workshop brought together biological and geological specialists on the lake and its surroundings to prioritize paleobiological, ecological and microbiological objectives that could ultimately be incorporated into an overall drilling plan for Lake Tanganyika and to consider how biological objectives can effectively be integrated into the paleoclimate and tectonics objectives of a Lake Tanganyika drilling project already considered in prior workshops.
\end{abstract}

\section{Introduction}

Understanding how ecosystems are assembled and altered through time, and understanding how the interplay between speciation, dispersal and extinction shapes species assemblages and communities, have been fundamental problems in both ecological and evolutionary sciences going back to the time of Darwin (1859). Evolutionary - in many cases adaptive - radiations in quasi-insular settings provide outstanding laboratories to address these questions (Losos and Ricklefs, 2009). Integral to advancing our understanding of the dynamics of the processes that underlie diversification is a need for long and highly resolved time series of community and habitat structure and individual species characteristics (morphological and genetic) that can supplement the shortterm "snapshots" we obtain from studying extant species and species interactions alone (e.g., Vermeij, 1994). It has long been understood that the incorporation of fossil information fundamentally improves the accuracy of phylogenetic trees, and our testable hypotheses of how groups of organisms have diversified (or disappeared) through time (e.g., Donoghue, 1989), while in-depth knowledge of past environmental conditions allows the identification of possible triggers of diversification events. Fossil records from the deposits of ancient lakes provide an important way to obtain such information. With their combination of long-term, continuous sedimentation providing environmental context and in situ speciation, the fossils and sediments of ancient lakes are ideal building blocks for making fundamental advances in understanding the processes underlying adaptive radiation, extinction and the development of complex species interactions (Rossiter and Kawanabe, 2000; Cohen, 2012; Wilke et al., 2016).

Among the ancient lakes of the world, Lake Tanganyika stands out as an ideal site for such a study. It is the oldest 

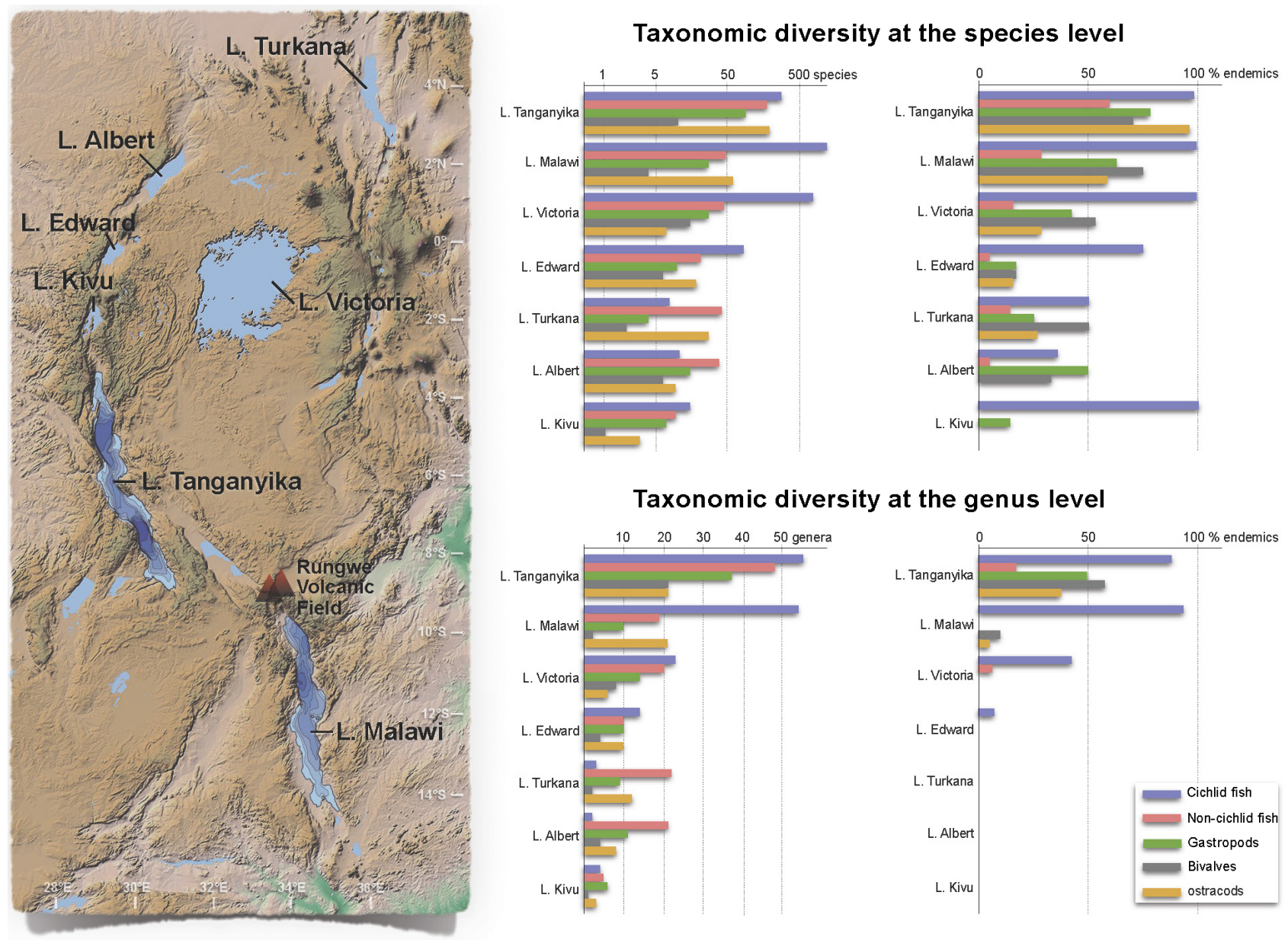

Figure 1. Taxonomic diversity of the African Great Lakes. The figure illustrates the unique characteristics of Lake Tanganyika's endemic diversity, where the age and persistence of the lacustrine environment is reflected in the large numbers and percentages of endemic genera among many groups of organisms in comparison to other lakes.

( $\sim 9-12$ Ma, Cohen et al., 1993), deepest $(\sim 1470 \mathrm{~m})$, and most voluminous $\left(18900 \mathrm{~km}^{3}\right.$ volume, $32600 \mathrm{~km}^{2}$ area) of the African Rift Valley lakes. The combination of its antiquity and size probably accounts for its extraordinary biodiversity, not only in sheer numbers of species found nowhere else in the world, but also in their morphological and behavioral distinctiveness and phylogenetic distance from their nearest relatives (Salzburger et al., 2014 and Fig. 1). This endemic biodiversity cuts across multiple large groups of animals, notably the cichlid fishes, and various groups of molluscs and crustaceans. Furthermore, all of these organisms have left interpretable records in fossils buried in the lake's sediments (e.g., Palacios-Fest et al., 2005).

Lake Tanganyika has previously been identified as a prime target for scientific drilling, and is the highest priority ancient lake still undrilled in Africa, based on its potential to also yield a unique and long record of tropical paleoclimate and tectonic processes in a very seismically active portion of the rift. Prior workshops have been held to consider these other science objectives of a Lake Tanganyika drilling campaign (Russell et al., 2012; McGlue and Scholz, 2016 workshop report). The combination of a long tectonic and climatic history of this lake has created an environmental framework of basin evolution and lake-level changes that in turn are likely primary drivers of the fascinating biological evolution observed in this lake.

\section{Workshop goals}

Over the course of a 3-day workshop held at the University of Basel, Switzerland, an international group of 25 biologists, paleoecologists and geologists considered the specifics of how a scientific drilling campaign at Lake Tanganyika might further advance our understanding of the lake's and its watershed's biotic history, and in turn make fundamental and transformative advances in our more general understanding of evolution in isolation and adaptive radiation among organisms. The workshop, sponsored by the Swiss National Sci- 
ence Foundation and the University of Basel, provided a first opportunity for specialists to consider specific strategies for drilling, core recovery and sampling of Lake Tanganyika's sedimentary record that would maximize the scientific impact of such an endeavor.

\section{Evolutionary biology and paleoecology objectives of a Lake Tanganyika Scientific Drilling Project}

An initial set of talks laid out some of the major paleobiological themes that could be pursued by a Lake Tanganyika Scientific Drilling Project (LTSDP) and set the stage for intensive discussions that occupied most of the workshop. Andy Cohen (University of Arizona) provided an overview of the project and the synergistic relationship of evolutionary biology/paleobiology objectives of the project to its other goals in paleoclimatology (Russell et al., 2012) and tectonics (McGlue and Scholz, 2016). Chris Scholz (Syracuse University) discussed our current understanding of subsurface seismic stratigraphy in Lake Tanganyika, which will be critical for identifying appropriate drilling targets to answer paleobiological questions (which are not necessarily the same as those optimal for paleoclimatology), as well as practical considerations for a drilling project in that lake. Because of its great depth and lack of seasonal overturn, Lake Tanganyika today is a stratified lake, oxygenated only within its upper layer (100-250 m), which limits the depth of benthic animal biodiversity. Besides, it has a surprisingly simplified pelagic ecosystem in comparison to the extraordinary diversity near its shores. Thus identifying drilling targets, which have regularly experienced lake floor oxygenation yet also are zones of quasi-continuous sedimentation, will be of paramount importance. James Russell (Brown University) discussed the potential of Lake Tanganyika as a long paleoclimate record of the Afrotropics. Lake Tanganyika's sensitivity to regional/global climate variability is well documented (Tierney et al., 2008; Otto-Bliesner et al., 2014), and this variability also forces changes in the lake's ecosystem over long timescales.

Walter Salzburger (University of Basel) focused on the cichlid fish fauna of the lake, which, while not the most diverse in terms of numbers of species within a single African lake, undoubtedly contains the greatest breadth of morphological, ecological and behavioral variation of any lake in the world, rendering Lake Tanganyika's cichlids iconic examples of evolution in isolation and adaptive radiation (Fryer and Iles, 1972). The availability of a continuous paleoecoological record of the lake and of fish fossils, which are abundant in the lake's sediments, raises the possibility that our understanding of cichlid evolution could be greatly enhanced through scientific drilling. An especially exciting prospect, the collection of ancient DNA from fossil fish or other organisms in Lake Tanganyika, was discussed by Moritz Muschick (EAWAG). Obtaining an ancient DNA (aDNA) record of ci- chlids from older species, especially with an accompanying high-resolution paleoenvironmental record, would allow scientists for the first time to truly understand the dynamics and drivers of adaptive radiation. This would be a truly transformative advance for all of evolutionary biology. Although the current temporal range of successful aDNA studies is only a small fraction of the age of Lake Tanganyika, the field is advancing rapidly and progressively older analyses are being regularly reported (Hofreiter et al., 2014; Wade, 2015). Another promising direction for incorporating fossil materials into phylogenetic studies from Lake Tanganyika may also come from the emerging field of fossil protein sequencing (Service, 2015). Ellinor Michel, Jon Todd (Natural History Museum, London), and Bert Van Bocxlaer (Ghent University) discussed the scientific potential of a fossil record of the extraordinary diversity of molluscs (especially gastropods) of Lake Tanganyika. Understanding the timing and environmental drivers of diversification, and whether other groups of snails have dominated past communities and the context of the innovations in traits (some thought to be the product of coevolution between snails and their predators), would all provide fascinating questions for evolutionary studies. Philip Barker (Lancaster University) discussed the potential for evolutionary ecology studies of diatoms in Lake Tanganyika. While the levels of endemism are lower among single-celled algae compared to animals, diatoms will be critical for understanding the ecosystem dynamics of the lake, and particularly from the standpoint of nutrient cycling, pelagic productivity and potentially in concert with changes occurring in the lake's watershed (i.e., silica delivery as affected by grassland development). The evolution of the pelagic ecosystem and how it might be tracked with a drill core record was discussed in detail by Peter McIntyre (University of Wisconsin) and Catherine Wagner (University of Wyoming). The modern simple pelagic ecosystem actually involves highly specialized and endemic species. Whether this evolved early or late in the lake's history is as yet unknown.

A drill core from Lake Tanganyika would not only inform us about the lake's aquatic biological history, but also that of its watershed through pollen, phytolith and charcoal records. Sarah Ivory (Brown University) discussed how a vegetation record from the lake could give us a much clearer picture of the timing and dynamics of biogeographic assembly of tropical African vegetation. This is not only of theoretical interest, but could also help inform conservation biology strategies for these endangered communities in the future (e.g., Ivory et al., 2016). Rick Potts (Smithsonian Institution) also discussed the importance of a terrestrial environmental record extending back to the late Miocene for improving our understanding of the context of human evolution in Africa. Lake Tanganyika drill cores could provide a continuous record of environmental variability from the time of the human (hominin)/African ape evolutionary split, at a central location between the two major theaters of the hominin fossil record, in southern and eastern Africa. Ishmael Kimirei (Tanzania 
Fisheries Research Institute) discussed ways in which a scientific drilling project at Lake Tanganyika could enhance training and collaborative research opportunities for African scientists. It is critical for this project's success and in enhancing its broader impacts to involve African scientists as full partners from its inception.

\section{Recommendations of the workshop}

The breakout and plenary discussions that followed the presentations provided an opportunity for the group to make specific recommendations on key hypotheses that could be tested in paleoecology and evolutionary biology by drilling Lake Tanganyika and integrating drill core data with existing information from existing biogeographic and phylogenetic information. Specifically, attendees discussed favorable drilling localities and sampling and analytical strategies required to evaluate the hypotheses. Lake Tanganyika is comprised of three major basins (and several additional subsidiary basins, Ebinger, 1989), which may have played a critical role in structuring diversification and biogeography within the lake. Cycles of isolation and reconnection of populations may have been very important as drivers of speciation. Collection of drill cores from more than one basin could allow us to test the idea that the development of these three basins left a biogeographic imprint on evolution that persists today through faunal isolation during low lake stands. Also, it would let us examine how terrestrial vegetation has evolved not only in the southern parts of the basin, where vegetation is dominated by miombo woodland, but also further north, where a record of tropical wet forest typical of the Guineo-Congolian vegetation region is more likely to be obtained. Collecting drill cores over this north-south spatial range (Tanganyika is the longest freshwater lake in the world, extending from $\sim 3$ to $9^{\circ} \mathrm{S}$ ) would have to be weighed against the likelihood that better chronological control on individual cores will be possible further south in the lake in closer proximity to the Rungwe volcanic field, which generates volcanic tephras found in the lake (Tiercelin and Mondeguer, 1991). Considerable discussion centered around the critical need to accurately date interbasinal faunal changes, either directly through tephras and other materials, or by correlation from the more tephra-rich sediments of the southern part of the lake towards the northern basins far from volcanoes. The extent to which additional drill sites for paleobiological objectives can be added into a drilling program will need to be weighed against the necessity for recovery of multiple cores per site to ensure a high-quality chronology for the most stratigraphically continuous sites.

Extensive discussions were also focused on how to best obtain useful paleobiological samples from the drill cores. This may involve approaches to sampling and core handling that are quite different to the more traditional approaches emphasizing paleoclimatic records from lakes. One very promising approach may be continuous computerized tomography (CT) scanning of drill cores to search for wellpreserved fossils (Fig. 2). Without prescreening the cores by CT prior to splitting, articulated fish skeletons on bedding planes and macromolluscs throughout the core are both likely to be damaged or unlikely to be observed during core splitting and description. CT scans could also be enormously valuable to this project as a tool for directly quantifying fossil abundances, particularly if automated counting methods can be developed for image analysis of the scans. They may also offer a means of obtaining extremely highresolution paleobiological data throughout the core records on par with the geochemical and physical properties data that are now routinely obtained from core scanning. Turbidites, which are typically considered a nuisance in lake cores by paleoclimatologists, may actually yield important shallow-water fossils from intervals that are otherwise represented by deep-water sediments devoid of shallow-water taxa. Also, the large amount of core anticipated for a Lake Tanganyika drilling project, coupled with the large number of taxonomic specialists interested in obtaining samples from these highly fossiliferous sediments, will certainly require a different workflow in fossil processing than has occurred in past lake drilling projects. Lake Tanganyika sediments are likely to yield an extraordinary range of fossils (fish, molluscs, diatoms and other siliceous algae, ostracodes, pollen, phytoliths, macroplants, charcoal, chironomids, sponges, crabs and bryozoans are all well documented from the lake as fossils already). Considerable discussion therefore focused on appropriate sampling intervals for the science questions of interest that would allow comparative studies between taxonomic and ecologic groups at identical timescales and resolutions. This would greatly improve our ability to address broader issues such as the evolution of ecosystem complexity in Lake Tanganyika, pelagic/benthic or lake/terrestrial ecosystem coupling, and co-evolutionary questions. Our ability to do this will critically depend on developing a plan for sampling, processing, sharing and allocating limited core materials in an efficient and timely way and ensuring that data management is well organized for the large numbers of sample splits that will inevitably be generated. LacCore (where initial core description will likely be done) already utilizes sample tracking following System for Earth Sample Registration (SESAR) and International Geosample Number (IGSN) standards, but it will be imperative that downstream labs distributing more specialized sample splits also follow these same protocols. Because of the large amount of core expected to be recovered (several kilometers are likely), the group recognized the need for a stratified sampling approach with some evolutionary questions addressed with lower-resolution sampling throughout the record, whereas questions about ecological turnover would be studied at high resolution over targeted but short intervals (e.g., Jackson et al., 2015). 


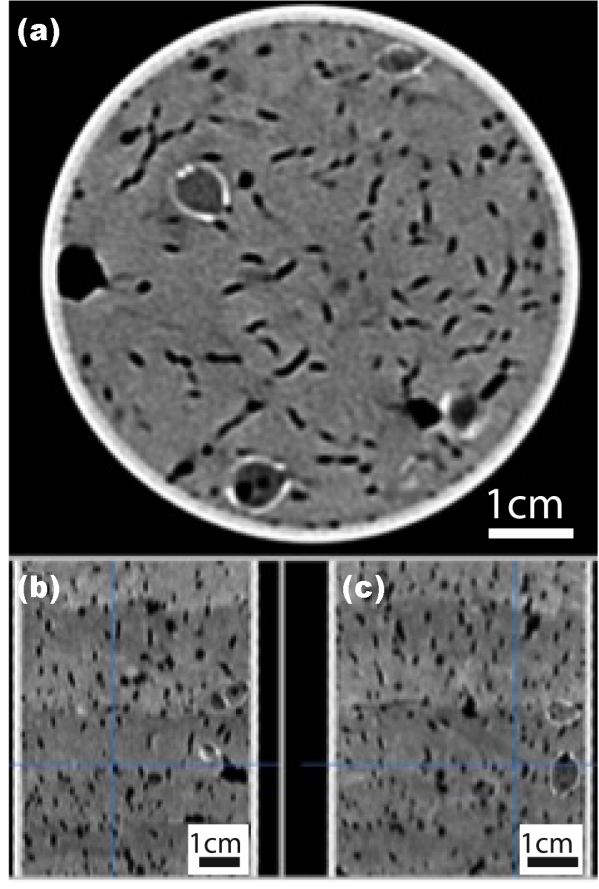

Figure 2. CT scan of a short core from Lake Wohlen (Wohlensee), Switzerland. The image courtesy of Hendrik Vogel and Flavio Anselmetti, and taken by Nicole Schwendener, was taken using the CT scanner at the Institute of Forensic Medicine, University of Bern. High-density bivalve shells appear as light, curved cross sections, whereas low-density voids appear dark, and the homogenous sediment matrix is intermediate in tone. (a) Cross-sectional view of the core. (b) and (c): lateral views of the core.

Discussions about aDNA and geomicrobiology components were focused on the practicalities of doing these types of studies on Lake Tanganyika cores. A roadmap for geomicrobiology studies exists from prior work at the Dead Sea, Lake Towuti, and other recent projects (e.g., use of fluorescent pigments in drilling fluids to track contamination and a GFZ mobile, on-site laboratory for sediment and porewater collection; see Ariztegui et al., 2015, for a detailed discussion). However, aDNA studies on lake cores are still in their infancy, and preliminary work is needed to determine the effective maximum age of fossil material that can be expected to yield aDNA from these types of tropical lake sediments. In the lead-up to drilling, pilot studies will therefore need to be done to assess the potential of obtaining aDNA from fossils other than fish, to determine ways to minimize the destructive aDNA sampling of valuable fossils, and to develop sequencing data for modern, closely related reference taxa (currently only comprehensively available for cichlid fish). These pilot studies will be critical for defining the exact science questions that can be realistically addressed with this approach as well as the appropriate sampling strategies. Also, aDNA and geomicrobiology samples will fall under a different set of international regulations regarding the export of biological samples than do typical core materials (e.g., the 2010 Nagoya Convention on Biological Diversity, in-country export regulations on biological materials), necessitating careful advance planning. This might provide a stronger impetus for in-country sample processing of geomicrobiological materials if possible. Obtaining optimal (i.e., large/intact) fossils for aDNA research probably should not rely on routine sieved macrofossil sampling of core splits, but should be more targeted. Locating these critical fossils from CT scans for both aDNA and morphological studies would not only ensure obtaining of the best samples for study with the least contamination, but would also avoid compromising the integrity of core materials for other purposes. Sample extraction for aDNA will require cleaner conditions than the initial core description (ICD) norm, involving surface decontamination with UV and bleach and UV treatment of water if sieved samples are to be used. Museum involvement will be critical for ensuring the long-term storage of unique fossil material collected by this project.

A final set of discussions focused on innovative funding, training and outreach opportunities for the biological aspects of a Tanganyika drilling project. As Ishmael Kimirei reiterated, early and continuous involvement with local partners will be critical, particularly given that many of the potential local biology and environmental science collaborators and institutions have no prior experience with scientific drilling. Participants in the workshop already have existing training and research partnerships with a number of institutions that could benefit from knowledge transfer and training opportunities related to this drilling project (e.g., the Tanzanian Fisheries Research Institute, The Hydrobiology Laboratory in Uvira, DRC, the University of Dar es Salaam Departments of Geology and Aquatic Sciences and Fisheries, the University of Zambia in Lusaka and the Department of Fisheries in Zambia, and the University of Burundi). The project would also develop new partnerships with organizations like the new Tanzanian National ICT Broadband Backbone (NICTBB http://www.nictbb.co.tz/index.php), the Tanzania Petroleum Development Corporation, the Nelson Mandela Institution of Science and Technology in Arusha, and the Tanzania National Parks Authority. Involving several of these applied agencies will help introduce the findings of conservation paleobiology obtained from core records into both terrestrial and lake management research strategies. There is also a potential for funding from large international donors for this component since the project is so highly interdisciplinary. Summer schools and training programs drawing on this interdisciplinary approach have already been very successful in training the upcoming generation of African environmental scientists (e.g., the Nyanza Project, www.geo. arizona.edu/nyanza/, and the Volkswagen Foundation Summer School series, http://www.geo.uni-potsdam.de/summer_ schools_en/articles/1805.html). These could have drilling science as a focus during the field campaign and ICD work. Numerous outreach/informal education strategies were also 
discussed. A Lake Tanganyika drilling project will be a large and highly visible endeavor and will need a strong and comprehensive outreach component that is integrated into project planning from the beginning. Target audiences will include local rural, urban African and international (US/European) people, and outreach strategies could include online multimedia platforms, film or video projects, local (lakeside) museum support, art displays and children's books. The project can draw on lessons learned in the region from prior outreach efforts related to scientific drilling and Lake Tanganyika (e.g., www.youtube.com/watch?v=B1iU0fBTfUw and https: //vimeo.com/78232028).

Over the next few years the team members involved in this workshop are looking forward to developing the exciting science prospects that would be provided by a Lake Tanganyika drill core record and developing strong interdisciplinary collaborations with the paleoclimate and tectonics teams of this project. Such an integrated study would truly transform our understanding of the long-term biological and environmental evolution of complex ecosystems.

Acknowledgements. This workshop was funded by grants from the Swiss National Science Foundation (SNF), the University of Basel, and the Center for African Studies of the University of Basel. We thank the Zoological Institute, University of Basel, for providing the venue, the Center for African Studies for assistance with conference travel and organization and all workshop participants for their contributions to this meeting and comments on earlier drafts of this paper. We thank Thomas Wilke and one other anonymous reviewer for many useful suggestions that improved this paper.

Edited by: T. Morishita

Reviewed by: T. Wilke and one anonymous referee

\section{References}

Ariztegui, D., Thomas, C., and Vuillemin, A.: Present and future of subsurface biosphere studies in lacustrine sediments through scientific drilling, Int. J. Earth Sci., 104, 1655-1665, 2015.

Cohen, A. S.: Scientific drilling and biological evolution in ancient lakes: lessons learned and recommendations for the future, Hydrobiologia, 682, 3-25, 2012.

Cohen, A. S., Soreghan, M., and Scholz, C.: Estimating the Age of Ancient Lake Basins: An Example from L. Tanganyika, Geology, 21, 511-514, 1993.

Darwin, C.: On The Origin Of Species By Means Of Natural Selection, 1st Edn., John Murray, London, 1859.

Donoghue, M. J.: The importance of fossils in phylogeny reconstruction, Ann. Rev. Ecol. Syst., 20, 431-460, 1989.

Ebinger, C.: Tectonic development of the western branch of the East African rift system, Geol. Soc. Am. Bull., 101, 885-903, 1989.

Fryer, G. and Iles, T. D.: The cichlid fishes of the great lakes of Africa: their biology and evolution, Oliver and Boyd, Edinburgh, 641 pp., 1972.
Hofreiter, M., Paijmans, J. L. A., Goodchild, H., Speller, C. F., Barlow, A., Fortes, G. G., Thomas, J. A., Ludwig, A., and Collins, M. J.: The future of ancient DNA: Technical advances and conceptual shifts, Bioessays, 37, 284-293, 2014.

Ivory, S., Regan, E., Sax, D., and Russell, J. M.: Niche expansion and temperature sensitivity of tropical African montane forests, Global Ecol. Biogeogr., 25, 693-703, 2016.

Jackson, L. J., Stone, J. R., Cohen, A. S., and Yost, C. L.: High resolution paleoecological records from Lake Malawi show no significant cooling associated with the Mount Toba supereruption at ca. $75 \mathrm{ka}$, Geology, 43, 823-826, 2015.

Losos, J. B. and Ricklefs, R. E.: Adaptation and diversification on islands, Nature, 457, 830-836, 2009.

McGlue, M. and Scholz, C.: Lake Tanganyika: A Miocene to Recent source-to-sink laboratory in the African tropics, STEPPE Workshop Report https://steppe.org/wp-content/uploads/reports/ Lake_Tanganyika_STEPPE_Workshop_Report_safe.pdf, 2016.

Otto-Bliesner, B., Russell, J. M., Clark, P. U., Liu, Z., Overpeck, J. T., Konecky, B., deMenocal, P. B., Nicholson, S. E., He, F., and Lu, Z.: Coherent changes of Northern and Eastern Equatorial African rainfall during the last deglaciation, Science, 364, 12231227, 2014.

Palacios-Fest, M. R., Alin, S. R., Cohen, A. S., Tanner, B., and Heuser, H.: Paleolimnological investigations of anthropogenic environmental change in Lake Tanganyika: IV. Lacustrine paleoecology, J. Paleolimnol., 34, 51-71, 2005.

Rossiter, A. and Kawanabe, H. (Eds.): The Biology of Ancient Lakes, Academic Press, San Diego, 2000.

Russell, J. M., Cohen, A. S., Johnson, T. C., and Scholz, C. A.: Scientific Drilling in the East African Lakes: A strategic planning workshop, Sci. Dril., 14, 49-54, doi:10.2204/iodp.sd.14.08.2012, 2012.

Salzburger, W., Van Bocxlaer, B., and Cohen, A. S.: The ecology and evolution of the African Great Lakes and their faunas, Ann. Rev. Ecol. Syst., 45, 519-545, 2014.

Service, R. F.: Protein Power, Science, 349, 372-373, 2015.

Tiercelin, J. J. and Mondeguer, A.: The geology of the Tanganyika trough, in: Lake Tanganyika and its Life, edited by: Coulter, G. W., Oxford U. Press, London, 7-48, 1991.

Tierney, J. E., Russell, J. M., Huang, Y., Sinninghe Damsté, J. S., Hopmans, E. C., and Cohen, A. S.: Northern Hemisphere Controls on Tropical Southeast African Climate During the Past 60,000 Years, Science, 322, 252-255, 2008.

Vermeij, G. J.: The evolutionary interaction among species: Selection, Escalation and Coevolution, Ann. Rev. Ecol. Syst., 25, 219236, 1994.

Wade, L.: Breaking a tropical taboo, Science, 349, 370-371, 2015.

Wilke, T., Wagner, B., Van Bocxlaer, B., Albrecht, C., Ariztegui, D., Delicado, D., Francke, A., Harzhauser, M., Hauffe, T., Holtvoeth, J., Just, J., Leng, M. J., Levkov, Z., Penkman, K., Sadori, L., Skinner, A., Stelbrink, B., Vogel, H., Wesselingh, F., and Wonik, T.: Scientific drilling projects in ancient lakes: Integrating geological and biological histories, Glob. Planet. Change, 143, 118151, 2016. 